\title{
How, When, and Where New Inhibitory Neurons Release Neurotransmitters in the Adult Olfactory Bulb
}

\author{
Cedric Bardy, ${ }^{1,2}$ Mariana Alonso, ${ }^{1,2}$ Walid Bouthour, ${ }^{1,2}$ and Pierre-Marie Lledo ${ }^{1,2}$ \\ ${ }^{1}$ Laboratory for Perception and Memory, Institut Pasteur, and ${ }^{2}$ Centre National de la Recherche Scientifique, Unité de Recherche Associée 2182, F-75724 \\ Paris Cedex 15, France
}

\begin{abstract}
Adult-born neurons continuously incorporate into the olfactory bulb where they rapidly establish contacts with a variety of synaptic inputs. Little is known, however, about the functional properties of their output. Characterization of synaptic outputs from new neurons is essential to assess the functional impact of adult neurogenesis on mature circuits. Here, we used optogenetics to control neurotransmitter release from new neurons. We found that light-induced synaptic GABA release from adult-born neurons leads to profound modifications of postsynaptic target firing patterns. We revealed that functional output synapses form just after new cells acquire the faculty to spike, but most synapses were made a month later. Despite discrepancies in the timing of new synapse recruitment, the properties of postsynaptic signals remain constant. Remarkably, we found that all major cell types of the olfactory bulb circuit, including output neurons and several distinct subtypes of local interneurons, were contacted by adult-born neurons. Thus, this study provides new insights into how new neurons integrate into the adult neural network and may influence the sense of smell.
\end{abstract}

\section{Introduction}

Altman and Das (1965) provided the first evidence of newborn neurons in the adult rodent brain already half a century ago. Since then, persistent neuronal generation has been unequivocally demonstrated in virtually all mammals (Alvarez-Buylla and Lim, 2004; Ming and Song, 2005; Zhao et al., 2008), including humans (Eriksson et al., 1998). Neural stem cells in the subventricular zone (SVZ) and rostral migratory stream (RMS) continue to produce neuroblasts throughout life. These neuroblasts migrate to the olfactory bulb (OB), where they differentiate into two major classes of interneurons: the granule cells (GCs) and periglomerular cells (PGCs).

Olfactory GCs are the most abundant subtype of adult-born neurons integrated into the bulbar circuit (Lledo et al., 2006). They are also the largest population of neurons in the $\mathrm{OB}$, greatly out-numbering the output neurons (i.e., the mitral and tufted cells) by 100:1 (Shepherd et al., 2004). GCs are axonless inhibitory interneurons with a small basal dendrite and a longer distally branching apical dendrite. Mature GCs participate in sensory information processing by mediating GABAergic inhibi-

\footnotetext{
Received Aug. 30, 2010; revised 0ct. 3, 2010; accepted 0ct. 18, 2010.

This work was supported by the ERA-NET NEURON (FP6 2007-2010), the Fondation pour la Recherche Médicale "Equipe FRM," the Groupe AG2R, and the Ecole des Neurosciences de Paris. We thank Venkatesh Murthy and Martin Wienisch for providing us with lentivectors during pilot experiments (a collaboration supported by the Philippe Foundation), Karl Desseiroth for the ChR2-YFP plasmids, and Kerren Murray for constructing some of the lentivectors. We also thank Armen Saghatelyan for helpful advice on gephyrin staining protocols and Marta Pallotto for providing the data of the supplemental Figure 14 (available at www.jneurosci.org as supplemental material). We are also grateful to Sebastien Wagner for developing the LED stimulation system, and to Clement Canonne and Octave Etard for contributing to the development of customized analysis programs. We also thank all the member of the laboratory for helpful discussion.

Correspondence should be addressed to Pierre-Marie Lledo, Laboratory for Perception and Memory, Institut Pasteur, 25 rue du Dr. Roux, F-75724 Paris Cedex 15, France. E-mail: pmlledo@pasteur.fr.

DOI:10.1523/JNEUROSCI.4543-10.2010

Copyright $\odot 2010$ the authors $\quad 0270-6474 / 10 / 3017023-12 \$ 15.00 / 0$
}

tion of mitral/tufted cells at their apical output synapses (Shepherd et al., 2004). Recent studies have provided insight into the origin and development of new neurons in the adult brain, in particular elucidating the highly coordinated actions that drive the synaptic integration of newborn neurons into preexisting circuits (for review, see Zhao et al., 2008; Whitman and Greer, 2009). However, the nature of signals that adult-born neurons convey to the preexisting bulbar circuits remains to be identified.

A few studies have described the physiological intrinsic properties of adult-born neurons. In these studies great efforts have been made to determine the sequence and types of synaptic input that contact developing adult-born neurons (Belluzzi et al., 2003; Carleton et al., 2003; Mizrahi, 2007; Whitman and Greer, 2007; Grubb et al., 2008; Kelsch et al., 2008; Livneh et al., 2009; Panzanelli et al., 2009). Young adult born neurons are known to fire action potentials following synaptic integration (Carleton et al., 2003) and neurotransmitter vesicles have been observed close to putative release sites (Whitman and Greer, 2007; Kelsch et al., 2008). To fully elucidate the function of adult neurogenesis, it is now important to determine how and when new neurons start acting on identified postsynaptic targets.

We addressed these issues using viral-vector gene transfection with the photosensitive channelrhodopsin2 (ChR2) (Nagel et al., 2003; Zhang et al., 2007; Toni et al., 2008) to specifically study the synaptic outputs of new neurons in the adult $\mathrm{OB}$ circuitry. We demonstrated that we could precisely control the firing pattern of ChR2-transduced newborn cells by exposing cells to brief flashes of blue light. We evaluated the influence of photoactivated adultborn neurons on the firing pattern of mitral cells as well as the time required by new functional contacts to be operational. We also examined whether the transmitted signals change over time with the maturation of newborn neurons. Finally, we examined the identity of the postsynaptic neuronal targets that receive 
GABAergic inputs from adult-born neurons. This study provides new insights into the postsynaptic effects of adult-generated neurons integrated into the $\mathrm{OB}$ circuitry.

\section{Materials and Methods}

Animals. We used adult ( $>2$ months old; $n=104)$ male C57BL/6J mice (Centre d'Elevage Janvier, Le Genest Saint Isle, France) during the course of this study. Mice were housed under a $12 \mathrm{~h}$ light/dark cycle, with dry food and water available ad libitum. All procedures were in line with the European Communities Council Directive of 24 November 1986 (86/ 609/EEC) and the European Union guidelines, and were reviewed and approved by our Animal Welfare Committee of our institution.

Lentiviral vectors. A replication-deficient lentiviral vector based on the HIV virus was used to express the ChR2-YFP (yellow fluorescent protein) fusion construct driven by a synapsin promoter using plasmids generously provided by K. Deisseroth's research group. The concentration of lentiviral vector particles used was $12 \mathrm{ng}$ of P24/ $\mu$ l. P24 antigen content was assayed by ELISA (NEN). Average vector titers were in the order of $10^{10}$ transduction units $/ \mathrm{ml}$.

Stereotaxic injection. For stereotaxic injections of lentiviral vector, adult mice were anesthetized with intraperitoneal injections of xylazine (0.25 mg of xylazine in PBS injected into each mouse; Rompun, Bayer Health Care) followed by ketamine ( $\sim 3 \mathrm{mg}$ of ketamine in PBS per mouse; Imalgene, Merial). Mice were then mounted on a Kopf stereotaxic apparatus and small craniotomies were drilled above the injection sites. We performed virus injections into the RMS at the following coordinates in each hemisphere (Grubb et al., 2008): anteroposterior, +3.3 $\mathrm{mm}$ from bregma; mediolateral, $\pm 0.82 \mathrm{~mm}$ from bregma, dorsoventral, $-2.90 \mathrm{~mm}$ from pial surface (supplemental Fig. 1, available at www. jneurosci.org as supplemental material). Viral vector particles ( $200 \mathrm{nl}$ per site) were injected bilaterally using a nanoliter injector Nanoject II (Drummond Scientific Company) with a glass micropipette at a rate of $23 \mathrm{nl} / \mathrm{s}$. Animals were killed at the indicated survival times after vector injection. Examination of OB slices revealed YFP in new GCs and periglomerular neurons only, demonstrating the specific labeling of adultborn migrating neuroblasts by injection of viral vector. We did not detect any diffusion from the injection site directly to the bulb. Additionally, no fibers coming from outside the OB were stained with YFP (supplemental Fig. 1, available at www.jneurosci.org as supplemental material).

By virally transducing a cohort of neuroblast en route to the $\mathrm{OB}$ with ChR2-YFP, we ensured that a large group of adult-born neurons specifically expressed ChR2 in the OB.

Slice preparation. Mice were deeply anesthetized with isoflurane (Mundipharma) and immediately decapitated. Brains were removed and horizontal slices (300 $\mu \mathrm{m}$ thick) were cut from the OB and frontal cortices. Brain removal and slicing were performed in oxygenated artificial $\mathrm{CSF}(\mathrm{ACSF})$ at $4^{\circ} \mathrm{C}$. After cutting, slices were maintained at $35^{\circ} \mathrm{C}$ for $20 \pm$ $10 \mathrm{~min}$, and kept in bubbled ACSF at $15-20^{\circ} \mathrm{C}$ before recordings were taken. The ACSF contained $124 \mathrm{~mm} \mathrm{NaCl}, 3 \mathrm{~mm} \mathrm{KCl}, 1.3 \mathrm{~mm} \mathrm{MgSO}_{4}, 26$ mм $\mathrm{NaHCO}_{3}, 1.25 \mathrm{~mm} \mathrm{NaHPO}_{4}, 20 \mathrm{~mm}$ glucose and $2 \mathrm{~mm} \mathrm{CaCl}$ (all chemicals from Sigma).

Whole-cell patch-clamp recordings. Individual slices were continuously perfused $(3 \mathrm{ml} / \mathrm{min})$ at room temperature $(\mathrm{RT})\left(\sim 25^{\circ} \mathrm{C}\right)$. For targeted whole-cell voltage-clamp recordings, we used a $40 \times$ water-immersion objective, differential interference contrast filters (all Olympus), a CCD camera (Hamamatsu C7500), a halogen (Olympus) or light-emitting diode (LED) arrays (Bridgelux) light source and a Heka EPC9/2 amplifier. The resistance of the patch electrodes was adjusted according to the size of the cell type being recorded $(\sim 11 \mathrm{M} \Omega$ for adult-born interneurons and $\sim 7 \mathrm{M} \Omega$ for mitral or tufted cells). Patch electrodes were filled with an internal solution containing $2 \mathrm{~mm} \mathrm{NaCl}, 10 \mathrm{~mm}$ Na-HEPES, $10 \mathrm{~mm}$ D-glucose, nucleotides ( $0.3 \mathrm{~mm}$ GTP, 2 mм Mg-ATP, 0.2 mM cAMP) and $0.15 \%$ biocytin and $0.06 \%$ rhodamine. For current-clamp experiments, the internal solution contained $130 \mathrm{~mm} \mathrm{~K}$-gluconate, $6 \mathrm{~mm} \mathrm{KCl}$ and 0.2 mM EGTA; in all other experiments, it contained $126 \mathrm{~mm}$ Cs-gluconate, 6 $\mathrm{mm} \mathrm{CsCl}$ and $0.2 \mathrm{~mm}$ Cs-EGTA. The $\mathrm{pH}$ and osmolarity of the internal solution were close to physiological conditions $(\mathrm{pH} 7.3,290-300$ $\mathrm{mOsm})$. Data were all corrected for liquid junction potentials $(10 \mathrm{mV})$.
Electrode capacitances were compensated on-line in cell-attached mode. Recordings were filtered at $10 \mathrm{kHz}$ (filter 1) and $2.9 \mathrm{kHz}$ (filter 2), digitized, and sampled at intervals of $20-50 \mu \mathrm{s}(50-20 \mathrm{kHz})$ according to specifications of individual protocols. To control the quality and the stability of the recordings throughout the experiments, access resistance, capacitance, and membrane resistance were monitored on-line.

Light stimuli. In preliminary experiments neuronal activity of adultborn neurons producing ChR2 was evoked using two blue LEDs (Platinum DRAGON LBW5SN $470 \mathrm{~nm}$ blue, OSRAM) positioned just above the slices $(\sim 9 \mathrm{~mm})$. Then, we stimulated ChR2 neurons with a powerful LED arrays (Bridgelux, cool white color spectrum) replacing the halogen light source transmission of the microscope. This improvement allowed us to get better consistency in the dose of light applied across experiments and to restrict the light stimulation on specific layers of the OB by reducing the opening of the microscope diaphragms. The maximum blue ( 470 $\mathrm{nm}$ ) light intensity applied to the entire OB slice was $\sim 9 \mathrm{~mW} / \mathrm{mm}^{2}$. This value was measured with a power meter (ThorLabs) directly on the setup. We also controlled that the intensity was homogenous in a diameter of at least $4 \mathrm{~mm}$ around the recorded cell. We varied the dose of light applied to the slices by changing the duration of exposure and occasionally the intensity of the LED. Closing down the diaphragms to spatially restrict the light beam also reduced the dose of light on the brain slice. To optimize the chance of detecting light-induced responses, in almost all cases, three consecutive pulses were delivered at $7.5 \mathrm{~Hz}$ and several sweeps were repeated at $10 \mathrm{~s}$ intervals. In voltage-clamp experiments each sweep contained a calibration test pulse $(-5 \mathrm{mV})$ for measurement of the access and membrane resistance and capacitance of the recorded cells. Due to electrical control of the light and imperfect grounding of the set-up, a fast rising artifact-like response to the onset and offset of the light were often observed (see, for example, Fig. $4 f$ ).

Minimal-light-evoked, and spontaneous, GABAergic synaptic currents. The evoked events by minimal light stimulation were analyzed off-line with custom designed Matlab programs (MathWorks). To distinguish the evoked responses from spontaneous ones, we compared the peak in a time window of $100 \mathrm{~ms}$ after the onset of light with the peaks in an equivalent time window in the absence of light. The amplitude, rise time $(20-80 \%)$ and decay time $(100-63 \%)$ of the peak currents in each trial were automatically measured and plotted. The properties of peaks that were evoked by spatially restricted and minimal light-stimulation of presynaptic neurons typically clustered in the plots. Those quantal responses, $7 \pm 4$ in 30 trials ( $77 \pm 13 \%$ failure rate) were then selected ( $n=$ 32 cells) and averaged to get the amplitude and kinetics of minimal-lightevoked IPSCs (min-eIPSCs). Few cells that appeared to have a mixture of different quantal evoked responses, even at minimal stimulation, were excluded from analysis. Spontaneous IPSCs (sIPSCs) were recorded over a period of 2-5 min. Spontaneous events properties were analyzed offline, using MiniAnalysis software (Synaptosoft) and detection threshold was set at $\sim 8-10 \mathrm{pA}$.

Immunohistochemistry. Recording pipettes were loaded with rhodamine and biocytin for identification of the morphology of recorded cells. The duration of whole-cell recordings was sufficient $(>30 \mathrm{~min})$ to allow rhodamine and biocytin diffusion into neuronal soma and complex dendritic arborization. Following recordings, pipettes were carefully removed and slices were fixed overnight in $4 \%$ paraformaldehyde (PFA) in phosphate buffer $(\mathrm{PB}), \mathrm{pH}$ 7.3. Slices which were processed more than a week after fixation were transferred into storing solution (25\% glycerol, $30 \%$ ethylene glycol, in PBS) and stored at $-20^{\circ} \mathrm{C}$. Slices were then washed in PBS and biocytin was labeled with a streptavidin Alexa Fluor 568 conjugate ( $1: 100$ from a stock solution of $1 \mathrm{mg} / \mathrm{ml}$ PBS containing $0.3 \%$ Triton X-100, $4 \%$ bovine serum albumin) for $2 \mathrm{~h}$ at RT. To enhance the fluorescence from ChR2-YFP ${ }^{+}$in adult-born neurons, YFP was labeled with anti-GFP (green fluorescent protein) antibody. Slices were treated (in PBS containing 0.3\% Triton X-100, 4\% bovine serum albumin, 5\% fetal calf serum; all from Sigma; $2 \mathrm{~h} \mathrm{RT}$ ) to block nonspecific binding sites and to permeabilize membranes. They were incubated overnight in primary antibody solution (rabbit anti-GFP IgG; 1:1000, Invitrogen) in blocking buffer at $4^{\circ} \mathrm{C}$, and then with secondary antibody (goat anti-rabbit Alexa Fluor 488; 1:500, Invitrogen) in PBS for $2 \mathrm{~h}$ at RT. 
Cell nuclei were stained with 4' $6^{\prime}$-diamidino-2-phenylindole dihydrochloride (DAPI) (1:5000; 5 min at RT).

For gephyrin immunostaining, slices were fixed after recording during $10 \mathrm{~min}$ in PFA $4 \%$, washed, stored at $4^{\circ} \mathrm{C}$ in PBS and processed no more than $3 \mathrm{~d}$ after fixation. Slices were washed in PBS containing $0.4 \%$ Triton $\mathrm{X}-100$ and incubated $2 \mathrm{~h}$ with $\mathrm{ABC}$ solution (Vector Laboratories) in the same buffer solution. Biocytin was labeled with streptavidin Alexa Fluor 568 conjugate ( $1: 200$ from a stock solution of $1 \mathrm{mg} / \mathrm{ml}$ PBS containing $0.4 \%$ Triton X-100) for $2 \mathrm{~h}$ at RT. To crosslink specific antibodies labeling and avoid any antibodies-antigen disruption slices were placed in PFA 4\% for $30 \mathrm{~min}$, washed in PBS and incubated $48 \mathrm{~h}$ in mouse antigephyrin (1:1000, Synaptic Systems) in combination with rabbit antiGFP (in PBS containing $0.4 \%$ Triton X-100, 4\% bovine serum albumin) at $4^{\circ} \mathrm{C}$. Finally, slices were incubated with secondary antibodies antimouse Alexa 633 (1/500) and anti-rabbit Alexa 488 (in PBS 0.4\% Triton $\mathrm{X}-100$ solution) for $2-3 \mathrm{~h}$ at RT.

Histological studies following electrophysiological recordings. Rhodamine diffused into the cells from the pipettes used during recordings. This allowed identification of the recorded cells before being fixed, giving valuable information about cell morphology and the position of recorded cell layer. One hundred and forty two neurons, which were filled with biocytin and counter-stained, were also imaged and analyzed in three dimensions by scanning confocal laser microscopy (LSM 510; Zeiss). Images were taken with a pinhole of $1 \mu \mathrm{m}$ using a Plan-Neofluar $25 \times$ [numerical aperture (NA), 0.8] and $63 \times(\mathrm{NA}, 1.4)$ objectives and stacks of optical slices $(0.5-1 \mu \mathrm{m}$ thick) were collected through the entire $z$-axis of each cell $(\sim 100 \mu \mathrm{m})$. Cell morphology was evaluated off-line in single optical planes and taken through the entire $z$-axis with LSM software (version 4.0, Zeiss). Based on morphology, location in the OB layers, and physiological features, recorded cells were confirmed as being mitral, tufted, juxtaglomerular, granule and short-axon cells (for more details, see supplemental Methods, available at www.jneurosci.org as supplemental material).

Quantification of gephyrin ${ }^{+} / \mathrm{FP}^{+}$puncta in mitral cell lateral dendrites. For several recorded mitral cells $(n=34)$, four regions on proximal dendrites (up to $100 \mu \mathrm{m}$ from the cell body) were imaged with a $40 \times$ objective (1.3 NA, $5 \times$ zoom) with a confocal microscope (Zeiss, LSM $700)$ using sequential acquisition of separate wavelength channels to avoid fluorescence cross talk. Stacks of $0.43-\mu \mathrm{m}$-thick optical slices were collected $(512 \times 512$ pixels $)$ with a pinhole set at 1 Airy unit. The number of gephyrin puncta located on the lateral dendrite of the biocytin labeled mitral cell were counted with Imaris software (version 7.0; Bitplane). For each image, background was subtracted and a Gaussian filter was applied. Mitral cell dendrite (red channel) was modeled as a volume, and estimated dendritic volume was automatically calculated. Gephyrin puncta present in the image were defined based on intensity $(>10-16 \%$ of maximal intensity) and size (minimal area $0.07 \mu \mathrm{m}^{2}$ ), and tagged as single spots. Spots were then filtered to select only those contacting the mitral cell dendrite surface. The formation of inhibitory synapses between $\mathrm{YFP}^{+}$newborn granule cells and recorded mitral cells was assessed by detecting YFP staining apposed to defined gephyrin spots. Spots of proximal YFP staining and Gephyrin puncta were automatically detected based on the mean intensity of YFP staining colocalized with each gephyrin spot ( $8-15$ gray values over background level) and was visually confirmed along the entire 3D reconstruction (see supplemental Movie, available at www.jneurosci.org as supplemental material). To obtain the average value of gephyrin ${ }^{+}$puncta (gephyrin spots) and gephyrin ${ }^{+} /$ $\mathrm{YFP}^{+}$contacts for each cell, data collected from 4 images were averaged. The quantitative analyses were performed blind to the times postinjection of each experiment.

Statistical analyses. Statistical analyses were performed with Prism software. All datasets were described using the mean \pm SEM. Since statistical analysis was mostly performed on groups that were often too small $(n<50)$ to estimate sample normality, we used nonparametric tests. Statistical differences between cell groups were compared with the nonparametric Mann-Whitney $U$ test or Wilcoxon for paired analysis.

\section{Results}

GCs receive several types of excitatory synaptic inputs that depolarize their membrane potential (Balu et al., 2007). To selectively excite a subset of adult-born interneurons, mostly including GCs, we chose to use the optogenetic technique. We stereotaxically injected a lentiviral vector, encoding ChR2-YFP under the control of the synapsin promoter into the RMS of 104 adult mice to obtain a population of light-sensitive adult-generated neurons. (Fig. 1a). We then performed patch-clamp experiments on acute horizontal $\mathrm{OB}$ slices taken from mice at different time points after vector injections, ranging from $3 \mathrm{~d}$ postinjection (dpi) to 5 months postinjection (mpi). Most of the slices were fixed and processed for immunohistochemistry staining shortly after electrophysiological experiments (Fig. 1a; supplemental Fig. 1, available at www.jneurosci.org as supplemental material).

\section{Remote control of the firing activity of new neurons by light}

Neuroblasts are produced in the SVZ and migrate through the RMS to finally reach the OB in less than a week. We selectively transduced a population of adult-born neurons with ChR2-YFP by focally injecting small quantity $(200 \mathrm{nl})$ of viral vector in the RMS. We carefully chose the injection site to be as remote as possible from both the SVZ and the OB. At 3 dpi no mature cells was found to express YFP. Most of the $\mathrm{YFP}^{+}$cells were in the core of bulb with a few immature neurons radially migrating in the granule cell layer (GCL). Together with the short life of the virus at $37^{\circ} \mathrm{C}(<24 \mathrm{~h})$, these observations preclude the possibility that the viral vector diffuses far away from the injection site (see also Grubb et al., 2008; Panzanelli et al., 2009). To control ChR2 in adult-born neurons, we performed ex-vivo patch-clamp recordings from newborn GCs expressing the ChR2-YFP construct (Fig. $1 b)$. Once sufficiently mature to generate action potentials $(>7$ dpi), all new neurons recorded were able to fire action potentials upon exposure to light stimuli ( 13 cells recorded in cell-attached mode and 27 cells recorded under the whole-cell configuration) (Fig. 1c, left and top-right). After a brief delay, the action potentials followed the light-induced inward currents mediated by ChR2 in newborn neurons (Fig. $1 c$, right-bottom). This first set of experiments demonstrates that the firing activity of newborn neurons was remotely and consistently controlled by shortduration (1-15 ms) light stimuli. We then determined whether the specific light-induced excitation of the newborn cells could trigger the release of neurotransmitters onto postsynaptic targets.

\section{Light activation of new neurons inhibits postsynaptic targets}

We recorded mitral cells while stimulating adult-born neurons with flashes of light (Fig. 2a). Mitral cells are the principal output neurons of the $\mathrm{OB}$, directly relaying olfactory information from the first synapses in the glomeruli to several downstream cortical structures. We investigated whether specifically stimulating new neurons could precisely modulate the firing patterns of mitral cells. To mimic physiological conditions, mitral cells were depolarized above the spiking threshold for a prolonged period (600$800 \mathrm{~ms}$ ), and several pulses of light were repeatedly applied to stimulate the light-sensitive new neurons. Adult-born neurons strongly inhibited the firing of action potentials from mitral cells through postsynaptic activation of $\mathrm{GABA}_{\mathrm{A}}$-receptors (Fig. $2 b, c$; see also supplemental Fig. 2, available at www.jneurosci.org as supplemental material). To more precisely examine the effect of evoked IPSCs (eIPSCs) on membrane potential, light-induced responses were recorded at various holding membrane potentials. As shown in Figure $2 d$, the current-voltage $(I-V)$ relation- 


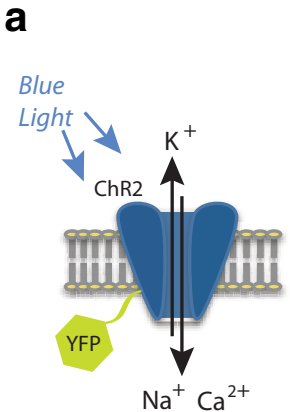

b

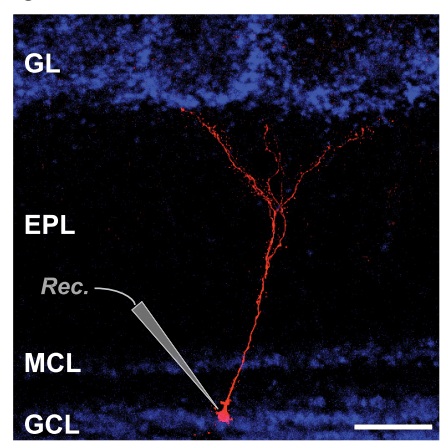

Lentiviral vector encoding ChR2-YFP

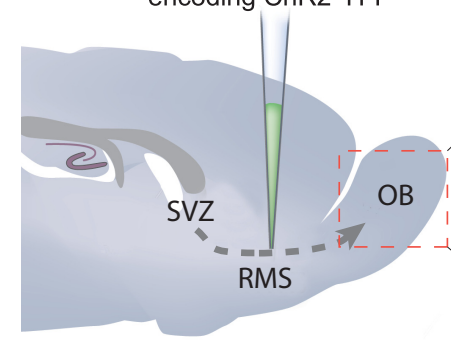

Adult-born neurons expressing ChR2-YFP

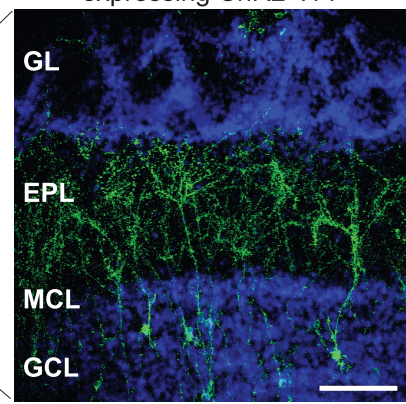

Figure 1. Remote control of adult-born neurons activity by light. $\boldsymbol{a}$, Left, The ionotropic ChR2 is transiently activated by flashes of blue light ( $\sim 470 \mathrm{~nm})$. Middle, To specifically express ChR2-YFP onto adult-born neurons, we performed stereotaxic injections of lentiviral vectors into the RMS. Right, Confocal image of an OB slice fixed after electrophysiological recordings. This photo shows the immunoreactivity of ChR2-YFP in adult-born neurons (green) and DAPI staining in all cell nuclei (blue). Scale bar, $100 \mu \mathrm{m}$. $\boldsymbol{b}$, Confocal images showing a patch-clamped adult-born GC filled with biocytin (red) and producing ChR2-YFP (green). The green channel was intentionally removed in the image on the left for clarity. The different OB layers are visible with DAPI staining (blue) (GL, glomerular layer; EPL, external plexiform layer; MCL, mitral cell layer; $G C L$, granule cell layer). Insets show the soma of a patch-clamp-recorded cell at higher magnification. Scale bars, $100 \mu \mathrm{m}$ (left) and $10 \mu \mathrm{m}$ (right). c, Effects of brief exposure to light in an adult-born GC transduced with ChR2-YFP. Light-evoked action potentials in cell-attached (left; mean trace of 10 trials) or in whole-cell recordings (top-right, current-clamp $-13 \mathrm{pA}, V_{\mathrm{m}} \approx-70 \mathrm{mV}$; black trace, mean; gray traces, 10 trials). Light-induced inward currents through ChR2 (right-bottom, voltage-clamp $-70 \mathrm{mV}$; black trace, mean; gray traces, 10 trials).

ship of the synaptic events was linear and was reversed at a membrane potential close to the $E_{\mathrm{Cl}}(-66 \mathrm{mV})$, when using a low internal chloride concentration $(8 \mathrm{mM})$. These results demonstrate the ability of adult-born interneurons to release GABA onto postsynaptic targets and tune the firing pattern of mitral cells in a repetitive manner.

Formation of new functional synaptic outputs to mitral cells Studies have reported that developing adult-born neurons receive synaptic inputs within a few days (Whitman and Greer, 2007; Grubb et al., 2008; Kelsch et al., 2008; Panzanelli et al., 2009). On the other hand, studies using synaptoporin or synaptophysin as a morphological surrogate for output synapses report a slow rate of maturation for output synapses, taking several weeks to develop (Whitman and Greer, 2007; Kelsch et al., 2008). We characterized this maturation rate using functional criteria. First, we examined the time course of the spiking probability of adult-born GCs stimulated by light. When new neurons just arrive in the GCL ( $\sim 3 \mathrm{dpi})$, the majority (6/7) were still unable to fire action potentials (observed in cell attached or current-clamp mode) despite the presence of small TTX-sensitive voltagedependent inward sodium currents (observed in voltage-clamp mode) (supplemental Fig. 13a,b, available at www.jneurosci.org as supplemental material). However, after 1 week postviral injection (wpi), virtually all GCs were spiking reliably (action potentials $>0 \mathrm{mV} ; n=20 / 20$ cells) (Fig. $3 a$; see also supplemental Fig. $13 c-e$, available at www.jneurosci.org as supplemental material).
Next, to determine the time course over which new functional synaptic outputs formed, we quantified the probability of recording light-evoked inhibitory postsynaptic currents (eIPSC) on mitral cells at different time points after injection of viral vector (from 13 dpi up to $5 \mathrm{mpi}$ ). To optimize the chance of stimulating adult-born neurons connected with a given recorded mitral cell, we used a large dose of light ( $\geq 15 \mathrm{~ms}-9 \mathrm{~mW} / \mathrm{mm}^{2}$ ) (see supplemental Fig. 3, available at www.jneurosci.org as supplemental material) and full-field stimulation. In our conditions, we found that even at lower expression level of ChR2 reached at early stages ( $\sim 1$ wpi), the light-evoked ChR2 currents were sufficient to reliably trigger action potentials in virtually all new neurons that were mature enough to fire action potentials ( $>1 \mathrm{wpi}$ ) (Fig. $3 a$; supplemental Figs. 12a,b, 13, available at www.jneurosci.org as supplemental material). To avoid any sampling bias, the present analysis excluded all mitral cells with sIPSC frequencies lower than $0.5 \mathrm{~Hz}$, and/or sIPSCs median amplitudes lower than $18 \mathrm{pA}$, and shortly cut apical or lateral dendrites (supplemental Fig. 4, available at www.jneurosci.org as supplemental material).

The earliest functional synaptic outputs were detected at 13 dpi $(n=3$ cells $)$, and were abolished in the presence of the $\mathrm{GABA}_{\mathrm{A}}$ receptor antagonist Gabazine $(10 \mu \mathrm{M}$; Fig. $3 b)$. Nevertheless, those early functional contacts were relatively rare ( $6 / 28$ cells tested between 13 and $18 \mathrm{dpi}$; Fig. $3 a$ ). In contrast, the percentage of mitral cells functionally connected by $\mathrm{ChR} 2{ }^{+}$adult-born neurons increased dramatically between 4 and 6 wpi (14 dpi: 21\%; 4 wpi: $\sim 36 \%$ and 6 wpi: $\sim 94 \%$; Fig. $3 a$ ). We checked that the 
a

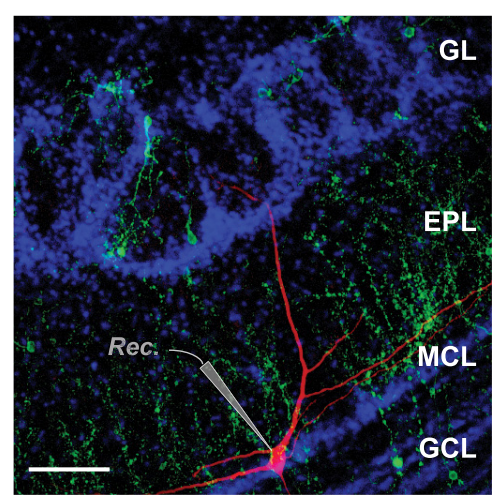

b
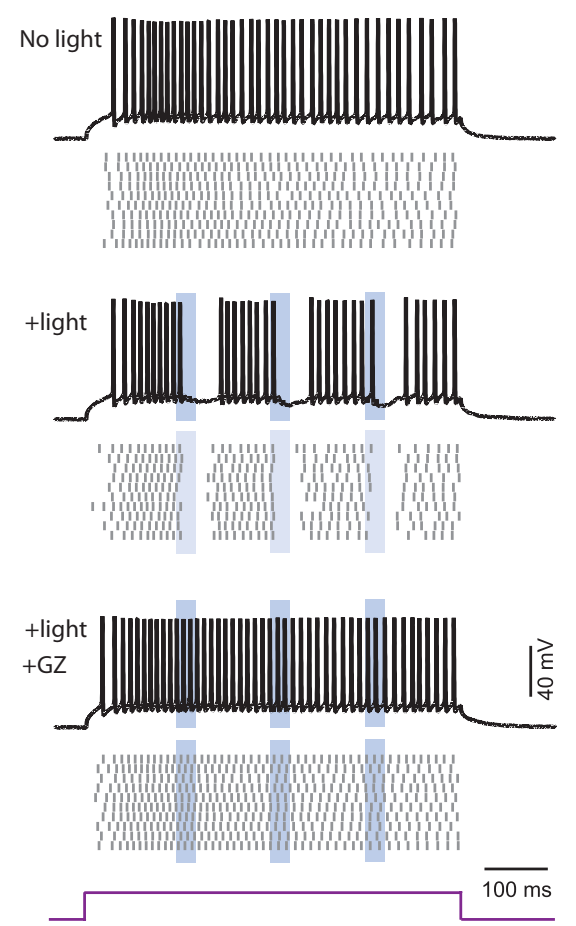

C

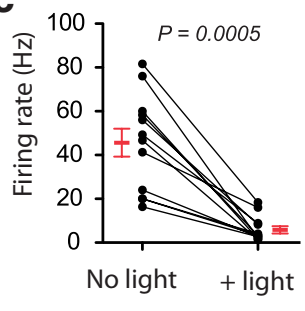

d
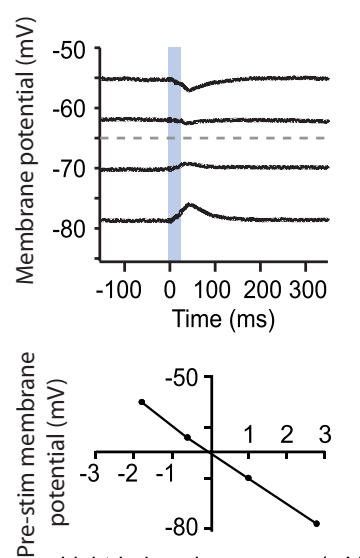

Light-induced responses $(\mathrm{mV})$

Figure 2. GABA released from adult-born neurons inhibits mitral cells. $\boldsymbol{a}$, Confocal image showing a patch-clamped mitral cell filled with biocytin (red) and adult-born neurons expressing ChR2-YFP (green). Scale bar, $100 \mu \mathrm{m} . \boldsymbol{b}$, Traces and raster plots (10 repeats) of current-clamp recordings showing the firing activity of a mitral cell, which was depolarized above spike threshold by injecting a steady current step (+100 pA). Mitral cell firing was repeatedly inhibited by blue light activation of adult-born neurons. The Gabazine (GZ) blocked the light-evoked inhibition. $c$, The firing rate was measured in a time window $(50 \mathrm{~ms})$ starting $10 \mathrm{~ms}$ after the onset of the first light stimulation and compared with the firing rate within the equivalent window in standard condition with no light stimuli ( $n=12$ mitral cells recorded at 17-21 wpi). $p$ value (Wilcoxon test) is shown in italics. $\boldsymbol{d}$, Current-clamp recordings of light-evoked postsynaptic potentials, either depolarizing or hyperpolarizing depending on the imposed membrane potential. The reversal potential of $\mathrm{Cl}^{-}$was $\sim-65 \mathrm{mV}$, corresponding to the reported resting membrane potential of mitral cells.

formation of new GABAergic contacts onto mitral cells was not caused by the continuous arrival of newly formed neurons. Immunohistochemical analysis of newborn neurons in the same slices that were used for patch-clamp recordings showed a rather stable ChR2-YFP ${ }^{+}$cell density between 2 wpi and 4 mpi (supplemental Fig. $5 a, b)$. The small number of $\mathrm{YFP}^{+}$cells expressing doublecortin-a marker of immature newborn neurons $(\sim 3 \%$ of cells at $3 \mathrm{mpi}$ )—further confirmed the absence of substantial ongoing recruitment of newborn cells expressing ChR2-YFP (supplemental Fig. $5 c$, available at www.jneurosci.org as supplemental material). Thus, the rapid increase in probability of detecting light-evoked GABAergic events in mitral cells after 4 wpi might result from an increase in the number of synaptic contacts being formed. This assumption was further tested by analyzing the presence of presynaptic YFP staining apposed to defined gephyrin clusters on the dendrites of the recorded mitral cells (Fig. 3c). Approximately 1 month after the new cells arrived in the $\mathrm{OB}$, we observed a significant increase in the density of gephyrinYFP contacts on the recorded mitral cells (before vs after 4 wpi; Mann-Whitney, $p<0.001$; Fig. $3 d, e)$. In contrast, the density of total gephyrin puncta on mitral cells remained constant (supplemental Fig. 6a, available at www.jneurosci.org as supplemental material).

Collectively, these data demonstrate that new GCs acquire the ability to fire action potentials within the first week after integration into the $\mathrm{OB}(\sim 1-2$ wpi). Almost immediately afterward, they start making functional output synapses (as early as 2 wpi), but the large majority of functional output synapses only appeared after 4 wpi. We therefore decided to examine whether the properties of functional synapses depended on the age of the adult-generated granule cells.

\section{Characteristics of synaptic outputs from adult-born granule cells}

Strong stimulations occasionally generated several spikes in ChR2 ${ }^{+}$neurons (supplementalFig. $7 a$, availableatwww.jneurosci. org as supplemental material) and, in some cases, may have simultaneously activated several adult-born neurons connected to the same mitral cell. To analyze the properties of eIPSCs from single pairs of presynaptic adult-born neurons and postsynaptic mitral cells, we gradually decreased the dose of light flashed to reveal a threshold of failure $(77 \pm 13 \%)$ interleaved with mineIPSCs (Fig. 4a). The min-eIPSCs were invariably blocked by bath application of the voltage-dependent $\mathrm{Na}^{+}$channel antagonist tetrodotoxin (TTX, $1 \mu \mathrm{M} ; n=22 / 22$ cells) (Fig. $4 b$; see also supplemental Fig. 8, available at www.jneurosci.org as supplemental material). To segregate the light-activated postsynaptic signals from noise or spontaneous activity, we carefully analyzed with the assistance of customized Matlab programs the current peaks in a time window of $100 \mathrm{~ms}$ after the light onset (Fig. $4 c$; see Materials and Methods). Figure $4 c$ illustrates that the unitary IPSCs (min-eIPSCs) obtained with minimal stimulation almost did not jitter. Bulbar adult neurogenesis produces several classes of interneurons, the vast majority being GCs and PGCs. Those two classes of cells are respectively found in the deep (GCL) and superficial [the glomerular layer (GL)] regions of the OB. To characterize the identity of the presynaptic neurons stimulated by light, we restricted photostimulation to a circular zone of $\sim 250$ 
$\mu \mathrm{m}$ in diameter, which was centered either in the superficial or deep layers (Fig. $4 d$; see also supplemental Fig. $9 a$, available at www.jneurosci.org as supplemental material and Methods). We never found eIPSCs distinguishable from sIPSCs when the light was focused in the GL (Fig. 4e). On the other hand, when the same spot of light was moved to the GCL, clear eIPSCs ( $n=14 / 14$ cells) were seen. They were nearly identical to those obtained with minimum full field stimuli (Fig. $4 f$ ). In these experiments, mitral cells were only selected if they had intact apical dendrites that reached the GL $(n=14 / 14)$. We also performed further controls to check the presence of distal responses. Despite possible filtering due to the distance between glomeruli and the mitral cell somata, we could still observe GABAergic responses evoked by local puffs of GABA receptor agonist ( $50 \mu \mathrm{M}$ muscimol) onto the distal portion of the apical dendrite in the GL (supplemental Fig. $9 b-d)$.

To test whether the nature of the output signals of new GCs differ over time, we analyzed the properties of min-eIPSCs at different time points, ranging from $13 \mathrm{~d}$ up to 5 months postinjection. The properties of min-eIPSCs from uncharacterized types of new neurons were not significantly different from those originating from focal light activation of GCs (Mann-Whitney: $p=0.98, p=0.49, p=$ 0.15 , for amplitude, rise and decay times, respectively). Therefore, we pooled both groups together for further analysis. Remarkably, the amplitude and kinetics of min-eIPSCs were constant regardless of the age of adult-born GCs (Fig. 5a). We then compared the properties of mineIPSCs with the properties of sIPSCs recorded on the mitral cells, assuming that sIPSCs represent synaptic contacts from broader populations of various interneurons (Fig. 5b). The amplitudes of mineIPSCs were significantly higher than the median values of the amplitudes of sIPSCs. We also found that min-eIPSCs were spike-dependent, whereas sIPSCs were virtually all spike-independent (sIPSCs frequency recorded in the presence of kynurenate was the same with or without TTX; see supplemental Fig. 10a, available at www.jneurosci.org as supplemental material). The amplitudes of sIPSCs were not normally distributed. Even in the presence of TTX, a considerable proportion $(>20 \%)$ of sIPSCs had amplitudes $>50 \mathrm{pA}$, like most min-eIPSCs (supplemental Fig. 10b, available at www. jneurosci.org as supplemental material). This suggests that adultborn GCs release larger quantities of GABA, or that new GABAergic synapses target a higher density of postsynaptic $\mathrm{GABA}_{\mathrm{A}}$ receptors than other interneurons contacting mitral green).
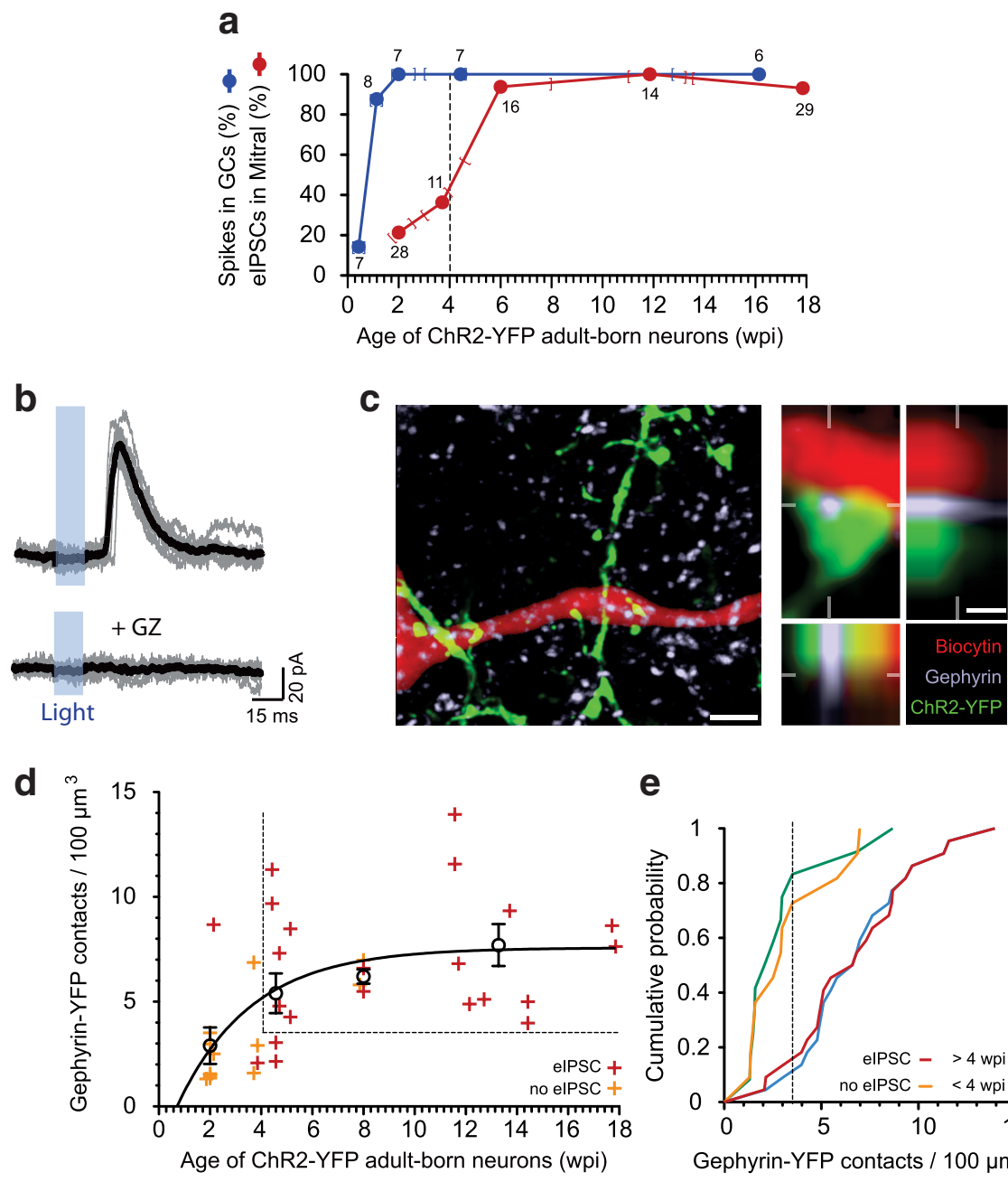

e

Figure 3. Time course of the formation of new functional synaptic outputs. $\boldsymbol{a}$, The blue points represent the proportion of GCS for a given time postinjection in which at least one of three consecutive full-field flashes $(7.5 \mathrm{~Hz})$ of blue light-evoked action potentials with $>0.8$ success rate. The red points represent the proportion of mitral cells for a given time postinjection in which elPSCs were clearly distinguishable from the spontaneous synaptic activity. The corresponding number of cells pooled together is shown next to each time point. The $x$-axis positions of each point represent the median of the time postinjection and the range is represented with the brackets on the connecting lines. The recorded mitral cells $(n=98)$ in the present sample had detectable lateral dendrites $(>100 \mu \mathrm{m})$ and homogenous sIPSCs frequencies and amplitudes (see supplemental Fig. 4, available at www. jneurosci.org as supplemental material). $\boldsymbol{b}$, Voltage-clamp recordings of a mitral cell (14 dpi) at $0 \mathrm{mV}$ illustrating light-induced postsynaptic inhibitory currents (eIPSCs; black traces, mean; gray traces, single sweeps). The responses disappeared in the presence of $\mathrm{GABA}_{\mathrm{A}}$ receptor antagonist (10 $\mu \mathrm{M} \mathrm{GZ}$ ). $\mathbf{c}-\boldsymbol{e}$, To assess the proportion of adult-born GABAergic synaptic contacts impinging onto mitral cells, we quantified the number of colocalized YFP and gephyrin puncta onto lateral dendrites of mitral cells $(n=34 / 98$ cells). Biocytin included in the patch-clamp pipette revealed recorded mitral cells. c, Example of a gepherin puncta colocalized with biocytin and YFP. Scale bar, $3 \mu \mathrm{m}$ (left) and $0.5 \mu \mathrm{m}$ (right). $\boldsymbol{d}$, The crosses represent the mitral cells in which light triggers IPSCs (red) or not (yellow). The circles represent the mean \pm SEM of groups pooled according to time postinjection. The data were fitted with a nonlinear one-phase association $\left(R^{2}=0.31\right)$. The vertical dashed line was drawn at 4 wpi. Beyond this time point, $90 \%$ of mitral cells received light-evoked IPSCs. The horizontal dashed line was drawn at 3.5 puncta/100 $\mu \mathrm{m}^{3}$. Beyond this value, $\sim 90 \%$ of mitral cells received light-evoked IPSCS. $e$, Cumulative probability of the mitral cells $(n=34)$ distinguished on the presence $(n=$ 22 ; red) or absence ( $n=12$; yellow) of elPSCs, and recorded at a time postinjection $>4$ wpi $(n=22$; blue) or $<4$ wpi $(n=12$;

cells. The kinetics of sIPSCs were similar to the kinetics of mineIPSCs and to previously reported values of sIPSCs (Lagier et al., 2007).

These results demonstrate that new GCs form major inhibitory contacts with mitral cells. Unexpectedly, unitary spikedependent output signals remain rather constant regardless of the times at which synapses are formed. We then tested whether adult-born neurons send functional signals on targets other than mitral cells. 


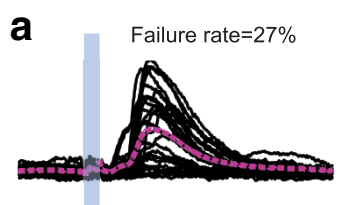

Supra-threshold stim. (5 ms)

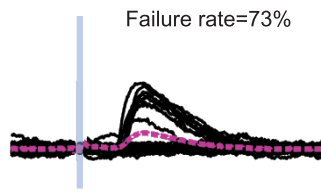

Minimal stim. (2 ms)

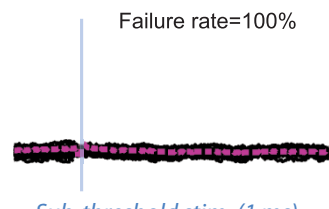

Sub-threshold stim. (1 ms)

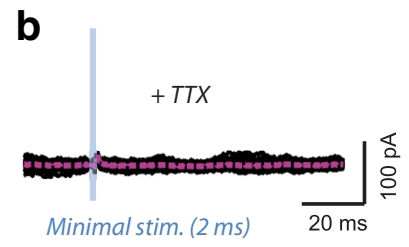

Min-eIPSCs

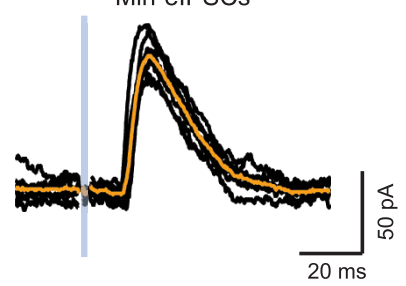

은 d

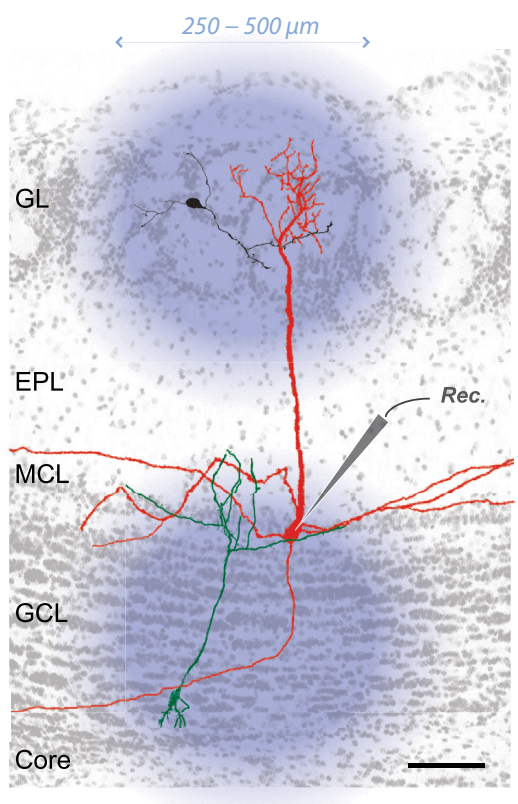

e

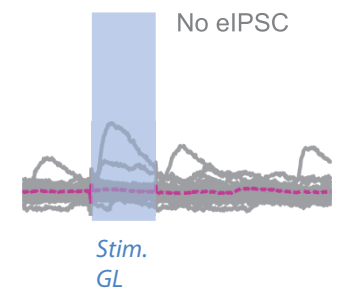

f

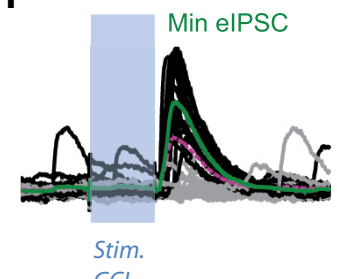

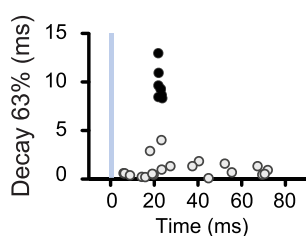

Time (ms)
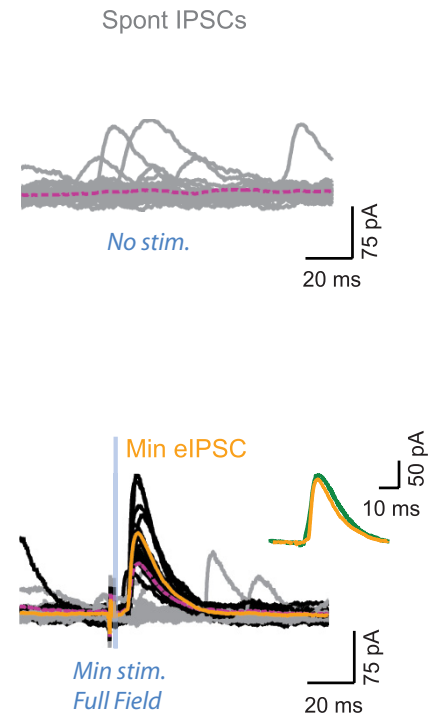

Figure 4. Restricted photostimulations of adult-born neurons in the OB. $\boldsymbol{a}$, Example of mitral cell IPSCs evoked by flashes of different duration. Black traces represent the individual trials $(n=30)$ while purple traces represent the average synaptic current including failures. The light duration was decreased progressively until elPSCs disappeared. The duration just above this threshold was chosen for the minimal stimulation. $\boldsymbol{b}$, IPSCS evoked by minimal stimulation (min-elPSCS) were blocked in presence of TTX (1 $\mu \mathrm{M})$. , , In standard condition (ACSF + kynurenate), clear quantal min-elPSC were selected and isolated from failure or eventual spontaneous events. The graphs represent the analysis of the peak currents in 30 trials, black circles for the selected trials and gray circles for the failures. The traces represent the trials in which a min-elPSC was identified with the assistance of customized Matlab programs measuring the properties of the peak within a time window following the onset of the stimulation (black; $n=7$ ) and the average (yellow). $\boldsymbol{d}$, Full-field illuminations were used to optimize the probability of finding presynaptic and postsynaptic pairs. To identify which class of adult-born neuron was stimulated (GC in green; PGC in black), light flashes were consecutively focused in the GCL and in the GL while recording the mitral cells (red). The diameter of the light spot varied between 250 and $500 \mu \mathrm{m}$ (see supplemental Fig. 9a, available at www.jneurosci.org as supplemental material). Scale bar, $100 \mu \mathrm{m} . \boldsymbol{e}$, Light restricted to the GL did not evoke IPSCs distinguishable from spontaneous IPSCS. $f$, In sharp contrast, the same stimulation focused in the GCL clearly evoked IPSCs similar to min-elPSCs obtained with minimal full-field stimulation. Identical results were obtained in all mitral cells tested similarly $(n=14)$. After recordings, all mitral cells were controlled to have intact apical dendrite reaching the $\mathrm{GL}$.

\section{Diversity of neurons targeted by adult-born interneurons}

Little is known about the identity of the postsynaptic bulbar neurons targeted by adult neurogenesis. We therefore randomly selected various putative postsynaptic targets from OB slices (1-4 mpi). We tested evoked postsynaptic responsiveness in a total of 118 putative target cells, comprising 76 output OB neurons (59 mitral and 17 tufted cells) and 42 local interneurons (18 granule, 15 juxtaglomerular, and 9 short axon cells). Surprisingly, we found that all major cell types of the OB circuit, including both output neurons and local interneurons, responded to light stimuli. Mitral and tufted cells, which project their axons to the cortex, were the predominant targets of GABAergic adult-born neurons ( $n=65 / 76$; Fig. 6a,b,d; supplemental Fig. 11, available at www.jneurosci.org as supplemental material). We also found that light stimulation elicited synaptic events at $O B$ intrinsic neurons $(n=9 / 42)$, including short axon cells, juxtaglomerular cells and GCs (Fig. 6a,c,d). For each cell type, light-induced events were blocked by bath application of TTX $(1 \mu \mathrm{M})$ but were partially restored by increasing the stimulus duration, which was indicative of direct monosynaptic contacts on the target cells. Application of Gabazine confirmed that evoked responses were mediated by $\mathrm{GABA}_{\mathrm{A}}$ receptor activation, independent of the target cell type. Overall, these findings show that both $\mathrm{OB}$ output neurons, and all major types of 
local interneurons, receive direct new GABAergic contacts from adult-born neurons.

\section{Discussion}

The main objective of the present study was to functionally characterize for the first time the synaptic outputs and neuronal targets of adult-generated neurons in the mature $\mathrm{OB}$ circuit. The development of genetic and optical techniques to control neuronal activity with high temporal resolution has widened the choice of tools available to study the synaptic organization of neuronal circuits. Here, we used ChR2 to remotely and simultaneously control the activity of a large subset of adult-generated neurons and identity the postsynaptic targets with patch-clamp recordings. This optogenetic approach turned out to be a very reliable and efficient alternative method to the tedious paired recording. We found that adultborn neurons could release GABA early during their maturation (i.e., within few days after cell transduction), although the majority of functional outputs were made a month later. Remarkably, once formed, the characteristics of postsynaptic signals issued from adult-born neurons do not change over time. Finally, this study also revealed the unexpected complexity of the identity of neuronal targets that receive outputs from new neurons.

\section{Formation of functional synapses from adult-born interneurons}

We found that the probability of finding a

functional GABAergic contact between a new neuron and a given mitral cell increases dramatically between 4 and 6 wpi. We demonstrated that this rise reflects an increase in the number of functional contacts rather than differences in presynaptic features (for example, light sensitivity or release probability). Despite the formation of new synapses, the total number of inhibitory contacts impinging onto mitral cells remains constant. In addition, the properties of quantal GABAergic postsynaptic signals (amplitude and kinetics) were also remarkably constant over time. Together these results imply that new GABAergic contacts rapidly substitute other inhibitory contacts. As proposed in the hippocampus (Toni et al., 2008), the newly formed synapses are likely to hijack preexisting synaptic contacts, although the mechanisms of this substitution remain unknown.

Time course of the functional integration of new neurons Neuroblasts are produced in the SVZ and migrate through the RMS to finally reach the OB in less than a week. The neuroblasts transduced with ChR2-YFP at our injection site in the RMS were born 3-4 d earlier. We observed the first neuroblasts becoming neurons and integrating the GCL 3 d later (see also Panzanelli et al., 2009). Less than 2 wpi, the passive membrane properties of the GCs reach maturity (Fig. 7; supplemental Fig. 12a,b, available at www.jneurosci.org as supplemental material) (see also Carleton et al., 2003; Nissant et al., 2009; Panzanelli et al., 2009). Unlike b
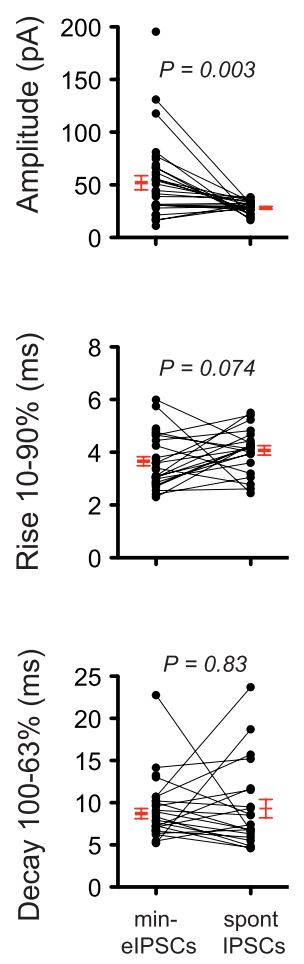

Figure 5. Properties of the postsynaptic GABAergic currents from adult-born granule cells. $\boldsymbol{a}$, We observed functional output signals first group. The linear fits were performed on the pulled dataset and did not significantly deviate from zero $\left(p>0.45 ; R^{2}<0.02\right) \cdot \boldsymbol{b}$, The properties of the min-eIPSCs (mean) and sIPSCs (median) were obtained in presence of kynurenate. Wilcoxon test $p$ values are shown in italics. The averages \pm SEM of the datasets are shown in red.

neurons in the developing brain, adult-born neurons face the additional challenge of integrating into a mature circuit without disrupting its ongoing function (Lledo et al., 2006; Whitman and Greer, 2009). For this reason, new neurons in the adult OB circuit have been suggested to develop input synapses well before the maturation of presynaptic GABAergic release sites (Whitman and Greer, 2007; Kelsch et al., 2008). Previous findings from immunostaining of presynaptic and postsynaptic markers and electrophysiological recordings of adult-born interneurons have demonstrated the rapid formation of GABAergic and glutamatergic input synapses on newborn GCs ( $\sim 1$ wpi) (Panzanelli et al., 2009). In the present study, we report that the maturation of voltage-dependent sodium currents occurred rapidly ( $\sim 1$ wpi) and lagged behind the maturation of voltage-dependent potassium outward currents ( $<3 \mathrm{dpi}$ ) (Fig. 7; supplemental Fig. 13a,b, available at www.jneurosci.org as supplemental material). New GCs acquired the ability to fire action potentials when the right balance between sodium and potassium currents was reached (<1 wpi) (see also Carleton et al., 2003; Wang et al., 2003). Soon after $(\sim 2$ wpi), we found that newborn neurons form the first functional GABAergic synapses with mitral cells. Nevertheless, the large majority of functional synapses are formed only a month later (Fig. 7). An increase in spine density also slightly preceded the increase of chances to record light-induced responses on mitral cells (Fig. 7, supplemental Fig. 14, available at 


\section{a}

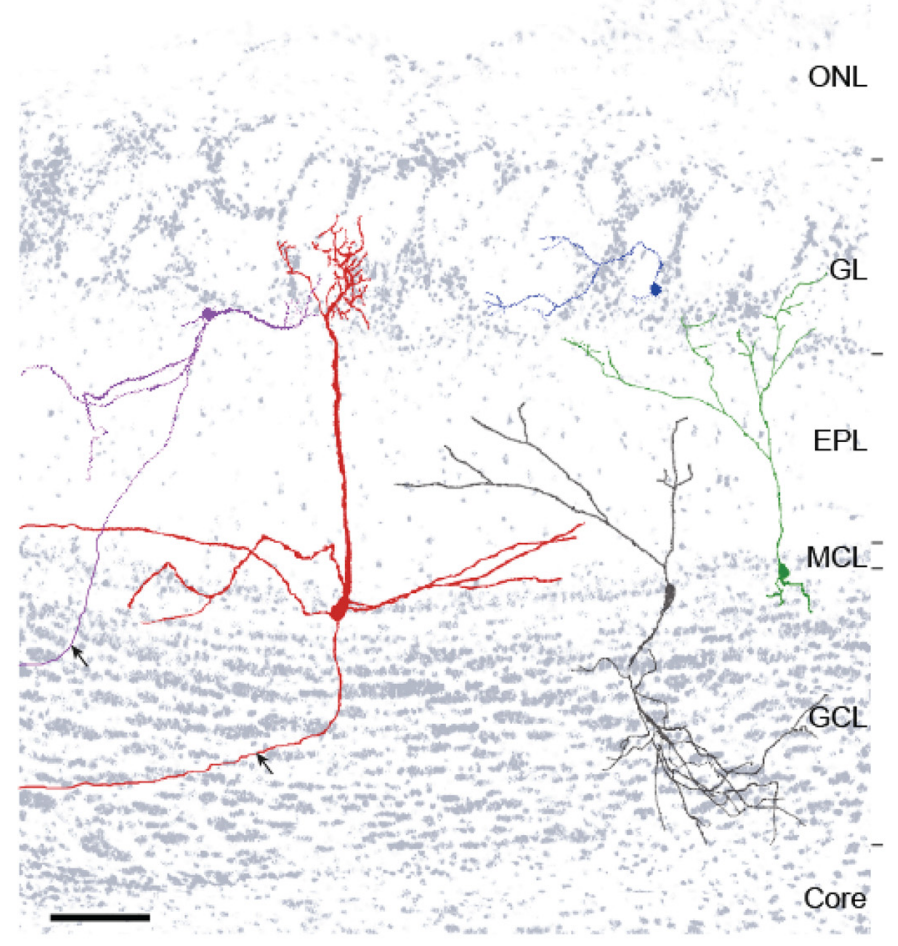

C

Short axon cell

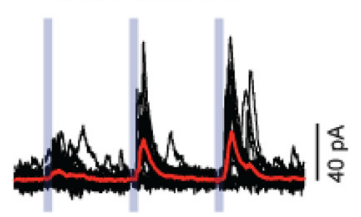

Juxtaglomerular cell
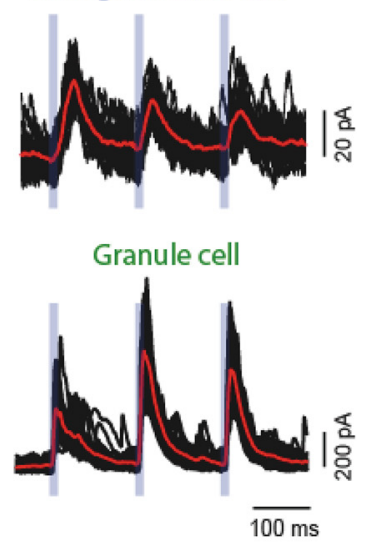

b

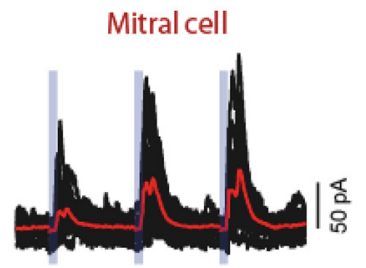

Tufted cell

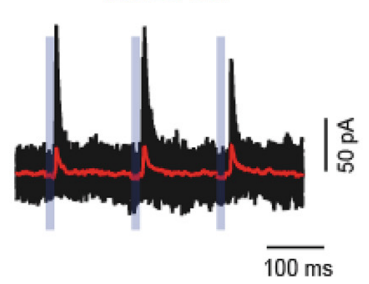

d

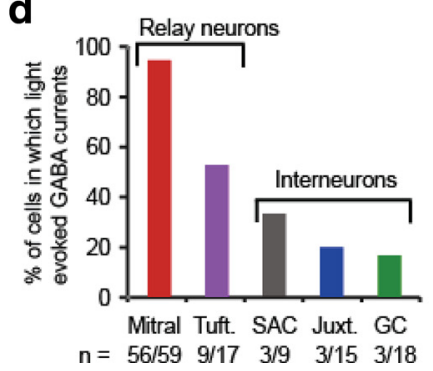

Figure 6. Postsynaptic targets of adult-born neurons are diverse. $\boldsymbol{a}$, Reconstitution of mitral (red), tufted (purple), juxtaglomerular (blue), granule (green), and short axon (dark gray) cells after patch-clamp recordings. These cell types all received inhibitory synaptic contacts from adult-born neurons. Images were obtained from confocal pictures of recorded cells filled with biocytin and immunolabeled with streptavidine-Alexa 568. The photos of each type of cell were superimposed on a DAPI-stained section (light gray background). The morphology and the positions of the cells were not modified (see supplemental Fig. 11, available at www.jneurosci.org as supplemental material). Scale bar, $100 \mu \mathrm{m} . \boldsymbol{b}, \boldsymbol{c}$, Adult-born neurons were stimulated with three consecutive blue light pulses $(15 \mathrm{~ms})$. The traces show voltage-clamp $(0 \mathrm{mV})$ recordings of the postsynaptic targets. Each sweep $(n=30)$ is shown in black and mean evoked currents in red. $\boldsymbol{d}$, Although functional contacts were recorded in all subtypes, the proportions of responsive cells were much higher in relay neurons (65/76) than in interneurons $(n=9 / 42)$. All of the elPSCs were obtained after 4 wpi.

www.jneurosci.org as supplemental material) (see also Whitman and Greer, 2007). This short delay probably reflects the time needed by new synapses to become functional. Altogether our data suggest that the incorporation of adult-generated interneurons is a complex, stepwise process that depends upon the sequential maturation of input synapses, voltage-dependent sodium and potassium currents, to form functional GABAergic synaptic outputs.

\section{Relative contribution of new neurons located in the deep or superficial layers}

Using spatially restricted photostimulations, we reveal that new GCs provide GABAergic inputs to mitral cells. Combined with minimal intensity light stimulation, we also demonstrate that single spikes in new GCs can trigger synaptic release of GABA. We therefore conclude that those postsynaptic signals are likely to occur in more "physiological" conditions (in vivo). In contrast, the lack of synaptic response when stimulating new neurons in the GL may be explained in three ways. First, it might be due to possible differences in the synaptic strength of output signals originating from new GCs or PGCs. Second, since inputs originating from the GL are remote from the recording site $(\sim 300$ $\mu \mathrm{m}$ ), it is possible that light-evoked synaptic responses generated in glomeruli are filtered through the length of the apical dendrite. Although, under the same experimental configuration, we could record currents evoked by focal application of GABA receptor agonists (muscimol) applied in the glomerulus, these muscimolinduced responses were always smaller than the ones elicited by identical application on lateral dendrites closer to the soma (see supplemental Fig. $9 b-d$, available at www.jneurosci.org as supplemental material). Finally, the respective proportions of new neuron subtypes demonstrate that bulbar neurogenesis is strongly biased toward GCs (i.e., the relative proportion of new neurons located in the GCL is $83 \pm 2 \%$ at $2-22 \mathrm{wpi} ; n=6$ mice and similar proportions were previously observed with vectors not encoding ChR2) (our unpublished data). Thus, it is no surprise that the present study essentially focuses on output signals generated from adult-born GCs. 


\section{Properties of new and old granule cell output signals onto preexisting mitral cells}

We previously demonstrated (Lagier et al., 2007) that mitral cells receive GABAergic contacts mediated either by $\mathrm{GABA}_{\mathrm{A}}$ receptors with $\alpha_{1}$ or $\alpha_{3}$ subunits, and exhibit typical kinetics. The comparison between our previous data and the kinetics of the light-induced signals suggests that inhibition provided by adultborn GCs is mediated by $\mathrm{GABA}_{\mathrm{A}}$ receptors bearing the $\alpha_{1}$ subunit. The similarity between the properties of GABAergic signals on mitral cells received from adult-born GCs of different ages $(\sim 2$ weeks vs 5 months) demonstrates that early formed synapses and older ones use identical inhibitory mechanisms, such as the types of receptors targeted and the localization of the contacts, at least during this time frame. It is unknown whether neurons having only just arrived into the bulb fulfill a particular function processing olfactory information. Put concisely, our findings suggest that the possible differences between young and old granule cells do not directly depend on basic properties of synaptic outputs but rather from the intrinsic properties of the GCs and their inputs.

Centrifugal excitatory synaptic inputs received by new GCs are prone to experience-dependent long-term potentiation (LTP) (Gao and Strowbridge, 2009; Nissant et al., 2009). The LTP response is strongest in GCs during early stages of maturation (2 wpi) (Nissant et al., 2009) when new neurons start being able to synaptically release GABA (the present study). The LTP then fades and disappears completely a few months later $(3 \mathrm{mpi})$. The functional benefit of this unique form of synaptic plasticity to newborn interneurons has yet to be demonstrated. Plastic centrifugal inputs may strengthen the influence of the minority of newborn GCs forming early functional synaptic outputs. Early functional outputs may play particular roles in the processing of olfactory information, which might be predominantly controlled by transiently plastic centrifugal inputs.

\section{Spike-independent GABA release}

In the postnatal SVZ, neuroblasts regulate proliferation of progenitors through nonsynaptic GABA signaling, which does not rely on spikes or $\mathrm{Ca}^{2+}$ currents (Liu et al., 2005). In the adult $\mathrm{OB}$, an intriguing feature of mature axonless GCs is their ability to release neurotransmitter through $\mathrm{Ca}^{2+}$ signals in the absence of action potentials. This was described for dendrodendritic synapses formed between mitral cells and GCs (Isaacson and Strowbridge, 1998; Halabisky et al., 2000; Egger, 2008).

In the present study, we showed that the postsynaptic GABA release triggered by relatively low light intensity was spikedependent and abolished in the presence of voltage-dependent sodium channel antagonist ( $1 \mu \mathrm{M}$ TTX; $n=22$ cells) (supplemental Fig. $8 a$, available at www.jneurosci.org as supplemental material). Nevertheless, we also found that increasing the intensity of light stimuli ( $>15 \mathrm{~ms} /$ full intensity) resumed GABA re- lease despite the continued presence of TTX ( $n=11 / 22$ cells; supplemental Fig. $8 a$, available at www.jneurosci.org as supplemental material). Bath application of a voltage-dependent $\mathrm{Ca}^{2+}$

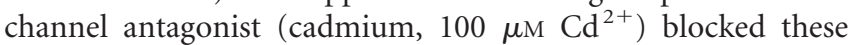
postsynaptic responses, demonstrating the requirement of $\mathrm{Ca}^{2+}$ currents to trigger GABA release ( $n=5 / 5$ cells) (supplemental Fig. $8 a$, available at www.jneurosci.org as supplemental material). These experiments demonstrate that if voltage-gated $\mathrm{Na}^{+}$ channels are not functional, a strong light-stimuli-induced depolarization is sufficient to recruit $\mathrm{Ca}^{2+}$ channels, thus allowing GABA release through an action potential-independent mechanism. This mechanism is similar to the characteristic traits of mature GABAergic spines of GCs (Isaacson, 2001). It raises an important question as to whether neuroblasts can release GABA before acquiring their ability to spike and integrate into the $\mathrm{OB}$ circuits, as shown under other circumstances (Liu et al., 2005). Our results also show that their actions may rely on at least two distinct mechanisms: one spike-dependent process likely to be involved in feedforward inhibition, and another spikeindependent process that potentially mediates local recurrent inhibition. The contribution of GABA release from young cells to lateral and reciprocal inhibition in mitral cells will have to be clarified in future studies.

\section{Diversity of postsynaptic targets of adult-born neurons}

Our study provided novel information on the identity of the postsynaptic targets of adult-generated $\mathrm{OB}$ interneurons. In the $\mathrm{OB}$, inputs from olfactory sensory neurons are relayed on to higher olfactory areas by the principal glutamatergic cells: the mitral and tufted cells (Shepherd et al., 2004). These principal 
cells are under the control of several neuronal cell types. In the GL, highly diverse PGCs convey signals to apical tufts of mitral and tufted cells through GABAergic transmission (Kosaka et al., 2001; Shepherd et al., 2004; Wachowiak and Shipley, 2006). In the external plexiform layer, axonless GCs establish reciprocal dendrodendritic synapses onto the lateral dendrites of mitral and tufted cells (Jahr and Nicoll, 1980; Chen et al., 2000; Smith and Jahr, 2002; Shepherd et al., 2004). As in many other brain regions, the GABAergic PGCs and GCs also receive GABAergic inputs (Price and Powell, 1970; Pinching and Powell, 1971; Puopolo and Belluzzi, 1998; Castillo et al., 1999; Nusser et al., 1999; Murphy et al., 2005; Pressler and Strowbridge, 2006), but the source of these inhibitory inputs is unclear. Two recent studies have demonstrated that $\mathrm{GCs}$ receive $\mathrm{GABA}_{\mathrm{A}} \mathrm{R}$-mediated inhibition from a subpopulation of inframitral short-axon cells, called Blanes cells (Pressler and Strowbridge, 2006) and from deep short-axon cells (Eyre et al., 2008). Adding further complexity to these local network interactions, our results demonstrate that adult-born interneurons contact not only the principal cell types, but also the three types of local interneurons, each of which is specialized to regulate network activity through the selective control of other OB neuronal partners. These GABAergic contacts were not just simple transient contacts; light-evoked responses persisted up to 4 months after viral injection. In addition, our findings show that adult-born interneurons can release GABA in the absence of spikes not only at dendrodendritic synapses formed with output neurons (mitral cells; $n=11 / 22$ tested cells in TTX) but also at synapses formed with local interneurons (GCs and short axon cells; $n=2 / 2$ tested cells). We conclude that adult-born neurons not only control the overall excitability in the OB circuit by impinging onto principal cells, but they may also disinhibit it by contacting the local inhibitory interneurons. Further experiments will be needed to demonstrate whether newborn GABAergic interneurons that contact principal cells differ substantially, or not, from those contacting local interneurons. The production of different neuronal subtypes targeting various postsynaptic neurons raises questions regarding how the correct ratios of interneuron types are maintained and how each newborn neuron finds its own target. It also remains unclear whether neuronal survival depends on the nature of the postsynaptic target.

\section{Potential outcomes of controlling the activity of adult-generated neurons}

The seminal discovery that new neurons are continuously added to the adult brain offers great hope for the design of novel strategies aimed at curing CNS dysfunction or trauma (Brüstle and McKay, 1996; Gage, 2000; Lie et al., 2004; Lindvall et al., 2004; Kokovay et al., 2008; McKay and Kittappa, 2008). We have demonstrated the feasibility of using optogenetics to precisely control the inhibitory output of adult-born interneurons, providing further evidence of the benefits of these new tools (Lagali et al., 2008; Toni et al., 2008; Gradinaru et al., 2009; Scanziani and Häusser, 2009). More work is clearly needed before we can foresee successful repair of complex neural networks following injury in humans. Nevertheless, we believe that understanding how newborn neurons naturally integrate into the mature CNS provides us with major advances in meeting this challenge. Our study contributes to this goal by providing functional evidence describing how, when, and where newborn inhibitory interneurons release neurotransmitters in the adult $\mathrm{OB}$.

\section{References}

Altman J, Das GD (1965) Post-natal origin of microneurones in the rat brain. Nature 207:953-956.

Alvarez-Buylla A, Lim DA (2004) For the long run: maintaining germinal niches in the adult brain. Neuron 41:683-686.

Balu R, Pressler RT, Strowbridge BW (2007) Multiple modes of synaptic excitation of olfactory bulb granule cells. J Neurosci 27:5621-5632.

Belluzzi O, Benedusi M, Ackman J, LoTurco JJ (2003) Electrophysiological differentiation of new neurons in the olfactory bulb. J Neurosci 23:10411-10418.

Brüstle O, McKay RD (1996) Neuronal progenitors as tools for cell replacement in the nervous system. Curr Opin Neurobiol 6:688-695.

Carleton A, Petreanu LT, Lansford R, Alvarez-Buylla A, Lledo PM (2003) Becoming a new neuron in the adult olfactory bulb. Nat Neurosci 6:507-518.

Castillo PE, Carleton A, Vincent JD, Lledo PM (1999) Multiple and opposing roles of cholinergic transmission in the main olfactory bulb. J Neurosci 19:9180-9191.

Chen WR, Xiong W, Shepherd GM (2000) Analysis of relations between NMDA receptors and GABA release at olfactory bulb reciprocal synapses. Neuron 25:625-633.

Egger V (2008) Synaptic sodium spikes trigger long-lasting depolarizations and slow calcium entry in rat olfactory bulb granule cells. Eur J Neurosci 27:2066-2075.

Eriksson PS, Perfilieva E, Björk-Eriksson T, Alborn AM, Nordborg C, Peterson DA, Gage FH (1998) Neurogenesis in the adult human hippocampus. Nat Med 4:1313-1317.

Eyre MD, Antal M, Nusser Z (2008) Distinct deep short-axon cell subtypes of the main olfactory bulb provide novel intrabulbar and extrabulbar GABAergic connections. J Neurosci 28:8217-8229.

Gage FH (2000) Mammalian neural stem cells. Science 287:1433-1438.

Gao Y, Strowbridge BW (2009) Long-term plasticity of excitatory inputs to granule cells in the rat olfactory bulb. Nat Neurosci 12:731-733.

Gradinaru V, Mogri M, Thompson KR, Henderson JM, Deisseroth K (2009) Optical deconstruction of parkinsonian neural circuitry. Science 324:354359.

Grubb MS, Nissant A, Murray K, Lledo PM (2008) Functional maturation of the first synapse in olfaction: development and adult neurogenesis. J Neurosci 28:2919-2932.

Halabisky B, Friedman D, Radojicic M, Strowbridge BW (2000) Calcium influx through NMDA receptors directly evokes GABA release in olfactory bulb granule cells. J Neurosci 20:5124-5134.

Isaacson JS (2001) Mechanisms governing dendritic gamma-aminobutyric acid (GABA) release in the rat olfactory bulb. Proc Natl Acad Sci U S A 98:337-342.

Isaacson JS, Strowbridge BW (1998) Olfactory reciprocal synapses: dendritic signaling in the CNS. Neuron 20:749-761.

Jahr CE, Nicoll RA (1980) Dendrodendritic inhibition: demonstration with intracellular recording. Science 207:1473-1475.

Kelsch W, Lin CW, Lois C (2008) Sequential development of synapses in dendritic domains during adult neurogenesis. Proc Natl Acad Sci U S A 105:16803-16808.

Kokovay E, Shen Q, Temple S (2008) The incredible elastic brain: how neural stem cells expand our minds. Neuron 60:420-429.

Kosaka K, Aika Y, Toida K, Kosaka T (2001) Structure of intraglomerular dendritic tufts of mitral cells and their contacts with olfactory nerve terminals and calbindin-immunoreactive type 2 periglomerular neurons. J Comp Neurol 440:219-235.

Lagali PS, Balya D, Awatramani GB, Münch TA, Kim DS, Busskamp V, Cepko CL, Roska B (2008) Light-activated channels targeted to ON bipolar cells restore visual function in retinal degeneration. Nat Neurosci 11:667-675.

Lagier S, Panzanelli P, Russo RE, Nissant A, Bathellier B, Sassoè-Pognetto M, Fritschy JM, Lledo PM (2007) GABAergic inhibition at dendrodendritic synapses tunes \{gamma\} oscillations in the olfactory bulb. Proc Natl Acad Sci U S A 104:7259-7264.

Lie DC, Song H, Colamarino SA, Ming GL, Gage FH (2004) Neurogenesis in the adult brain: new strategies for central nervous system diseases. Annu Rev Pharmacol Toxicol 44:399-421.

Lindvall O, Kokaia Z, Martinez-Serrano A (2004) Stem cell therapy for human neurodegenerative disorders-how to make it work. Nat Med 10 [Suppl]:S42-S50. 
Liu X, Wang Q, Haydar TF, Bordey A (2005) Nonsynaptic GABA signaling in postnatal subventricular zone controls proliferation of GFAPexpressing progenitors. Nat Neurosci 8:1179-1187.

Livneh Y, Feinstein N, Klein M, Mizrahi A (2009) Sensory input enhances synaptogenesis of adult-born neurons. J Neurosci 29:86-97.

Lledo PM, Alonso M, Grubb MS (2006) Adult neurogenesis and functional plasticity in neuronal circuits. Nat Rev Neurosci 7:179-193.

McKay R, Kittappa R (2008) Will stem cell biology generate new therapies for Parkinson's disease? Neuron 58:659-661.

Ming GL, Song H (2005) Adult neurogenesis in the mammalian central nervous system. Ann Rev Neurosci 28:223-250.

Mizrahi A (2007) Dendritic development and plasticity of adult-born neurons in the mouse olfactory bulb. Nat Neurosci 10:444-452.

Murphy GJ, Darcy DP, Isaacson JS (2005) Intraglomerular inhibition: signaling mechanisms of an olfactory microcircuit. Nat Neurosci 8:354-364.

Nagel G, Szellas T, Huhn W, Kateriya S, Adeishvili N, Berthold P, Ollig D, Hegemann P, Bamberg E (2003) Channelrhodopsin-2, a directly lightgated cation-selective membrane channel. Proc Natl Acad Sci U S A 100:13940-13945.

Nissant A, Bardy C, Katagiri H, Murray K, Lledo PM (2009) Adult neurogenesis promotes synaptic plasticity in the olfactory bulb. Nat Neurosci 12:728-730.

Nusser Z, Sieghart W, Mody I (1999) Differential regulation of synaptic GABAA receptors by cAMP-dependent protein kinase in mouse cerebellar and olfactory bulb neurones. J Physiol 521:421-435.

Panzanelli P, Bardy C, Nissant A, Pallotto M, Sassoè-Pognetto M, Lledo PM, Fritschy JM (2009) Early synapse formation in developing interneurons of the adult olfactory bulb. J Neurosci 29:15039-15052.

Pinching AJ, Powell TP (1971) The neuron types of the glomerular layer of the olfactory bulb. J Cell Sci 9:305-345.

Pressler RT, Strowbridge BW (2006) Blanes cells mediate persistent feedforward inhibition onto granule gels in the olfactory bulb. Neuron 49:889904.
Price JL, Powell TP (1970) The mitral and short axon cells of the olfactory bulb. J Cell Sci 7:631-651.

Puopolo M, Belluzzi O (1998) Inhibitory synapses among interneurons in the glomerular layer of rat and frog olfactory bulbs. J Neurophysiol 80:344-349.

Scanziani M, Häusser M (2009) Electrophysiology in the age of light. Nature 461:930-939.

Shepherd GM, Chen WR, Greer CA (2004) Olfactory bulb. In: The synaptic organization of the brain, Ed 5 (Shepherd GM, ed). New York: Oxford UP.

Smith TC, Jahr CE (2002) Self-inhibition of olfactory bulb neurons. Nat Neurosci 5:760-766.

Toni N, Laplagne DA, Zhao C, Lombardi G, Ribak CE, Gage FH, Schinder AF (2008) Neurons born in the adult dentate gyrus form functional synapses with target cells. Nat Neurosci 11:901-907.

Wachowiak M, Shipley MT (2006) Coding and synaptic processing of sensory information in the glomerular layer of the olfactory bulb. Semin Cell Dev Biol 17:411-423.

Wang DD, Krueger DD, Bordey A (2003) Biophysical properties and ionic signature of neuronal progenitors of the postnatal subventricular zone in situ. J Neurophysiol 90:2291-2302.

Whitman MC, Greer CA (2007) Synaptic integration of adult-generated olfactory bulb granule cells: basal axodendritic centrifugal input precedes apical dendrodendritic local circuits. J Neurosci 27:99519961.

Whitman MC, Greer CA (2009) Adult neurogenesis and the olfactory system. Prog Neurobiol 89:162-175.

Zhang F, Aravanis AM, Adamantidis A, de Lecea L, Deisseroth K (2007) Circuit-breakers: optical technologies for probing neural signals and systems. Nat Rev Neurosci 8:577-581.

Zhao C, Deng W, Gage FH (2008) Mechanisms and functional implications of adult neurogenesis. Cell 132:645-660. 